\title{
Bridging the membrane lipid divide: bacteria of the FCB group superphylum have the potential to synthesize archaeal ether lipids
}

\author{
Laura Villanueva $\mathbb{D}^{1,2} \cdot$ F. A. Bastiaan von Meijenfeldt $\mathbb{D}^{3} \cdot$ Alexander B. Westbye $\mathbb{D}^{1} \cdot$ Subhash Yadav $\mathbb{B}^{1} \cdot$ \\ Ellen C. Hopmans ${ }^{1} \cdot$ Bas E. Dutilh $\mathbb{1}^{3,4} \cdot$ Jaap S. Sinninghe Damsté $\mathbb{C}^{1,2}$
}

Received: 6 May 2020 / Revised: 10 August 2020 / Accepted: 2 September 2020 / Published online: 14 September 2020

(c) The Author(s) 2020. This article is published with open access

\begin{abstract}
Archaea synthesize membranes of isoprenoid lipids that are ether-linked to glycerol-1-phosphate (G1P), while Bacteria/ Eukarya produce membranes consisting of fatty acids ester-bound to glycerol-3-phosphate (G3P). This dichotomy in membrane lipid composition (i.e., the 'lipid divide') is believed to have arisen after the Last Universal Common Ancestor (LUCA). A leading hypothesis is that LUCA possessed a heterochiral 'mixed archaeal/bacterial membrane'. However, no natural microbial representatives supporting this scenario have been shown to exist today. Here, we demonstrate that bacteria of the Fibrobacteres-Chlorobi-Bacteroidetes (FCB) group superphylum encode a putative archaeal pathway for ether-bound isoprenoid membrane lipids in addition to the bacterial fatty acid membrane pathway. Key genes were expressed in the environment and their recombinant expression in Escherichia coli resulted in the formation of a 'mixed archaeal/bacterial membrane'. Genomic evidence and biochemical assays suggest that the archaeal-like lipids of members of the FCB group could possess either a G1P or G3P stereochemistry. Our results support the existence of 'mixed membranes' in natural environments and their stability over a long period in evolutionary history, thereby bridging a once-thought fundamental divide in biology.
\end{abstract}

These authors contributed equally: Laura Villanueva, F. A. Bastiaan von Meijenfeldt.

These authors jointly supervised this work: Bas E. Dutilh, Jaap S. Sinninghe Damsté.

Supplementary information The online version of this article (https:// doi.org/10.1038/s41396-020-00772-2) contains supplementary material, which is available to authorized users.

$\triangle$ Laura Villanueva

laura.villanueva@nioz.nl

1 NIOZ Royal Netherlands Institute for Sea Research, Department of Marine Microbiology and Biogeochemistry, Utrecht University, P.O. Box 59, 1797AB Den Burg, Texel, The Netherlands

2 Faculty of Geosciences, Department of Earth Sciences, Utrecht University, P.O. Box 80.021, 3508 TA Utrecht, The Netherlands

3 Theoretical Biology and Bioinformatics, Science for Life, Utrecht University, 3584CH Utrecht, The Netherlands

4 Centre for Molecular and Biomolecular Informatics, Radboud Institute for Molecular Life Sciences, Radboud University Medical Centre, Utrecht, The Netherlands

\section{Introduction}

Lipid membranes are essential for all cellular life forms to preserve the integrity and individuality of cells, as well as having a direct influence in the maintenance of energy metabolism. Lipid membranes are also key in differentiating the domains of life. Bacteria and eukaryotes have membranes formed by fatty acids linked to glycerol-3-phosphate (G3P) via ester bonds, while archaea have membranes made of isoprenoid alkyl chains linked by ether linkages to glycerol-1-phosphate (G1P), leading to an opposite stereochemistry of the glycerol phosphate backbone [1]. This segregation in lipid membrane composition, or 'lipid divide', has been hypothesized to have appeared early in the evolution of microbial life from the Last Universal Common Ancestor (LUCA), but the nature of the lipid membrane of LUCA and its subsequent differentiation in Bacteria and Archaea remain unknown. Some studies have proposed that a non-cellular LUCA lacked a lipid membrane [2-4]. A recent study suggested that the membrane of LUCA was formed by fatty acids and isoprenoids without the glycerol phosphate backbone as a requirement to have a lower membrane permeability that could sustain a proton 
gradient [5]. The most parsimonious hypothesis may be that LUCA had a heterochiral lipid membrane composed of both G1P and G3P together with fatty acids and isoprenoids $[6,7]$, which later diversified into archaeal and bacterial membranes resulting in the 'lipid divide'. It was originally proposed that this differentiation may have been driven by heterochiral membrane instability [8,9], but heterochiral membranes are in fact stable [10] and a recent study has proven that they are, in some cases, more robust to environmental stresses [11].

Another critical issue in the 'lipid divide' is the membrane lipid composition of eukaryotes. Multiple lines of evidence indicate that eukaryogenesis encompassed an endosymbiosis event of a bacterial cell into an archaeal host [12-17]. Thus, the bacterial-like composition of contemporary eukaryotic membranes implies that an early eukaryote had its archaeal-like membrane replaced by a bacterial-like one, possibly through a 'mixed membrane' intermediate containing both the archaeal membrane lipids with ether-linked isoprenoids to G1P and the bacterial ones with ester-linked fatty acids to G3P. This would imply that bacterial-like membrane molecules arose twice, in bacteria and in eukaryotes. The competing syntrophic hypothesis of eukaryogenesis [18-20] proposes that the host of the mitochondrial endosymbiont was a bacterium, avoiding the need for a transitional step from an archaeal to eukaryotic membrane. Some eukaryogenesis models also suggest that the membrane transition was facilitated by intensive bacterial lipid transfer from the endomembrane system [21]. Because most models for the origin of eukaryotes require a membrane transitional step similar to the one expected in the 'mixed membrane' scenario for LUCA, it is striking that no remnants or natural microbial representatives with a heterochiral 'mixed membrane' have yet been described that would support the viability of such a scenario.

The concept of the 'lipid divide' has been challenged by the identification of traits thought to be characteristic of archaeal membrane lipids in bacteria and vice versa, mostly restricted to specific taxonomic groups. First, some bacteria (and eukaryotes) produce ether-linked lipids [22-28]. Second, membrane-spanning lipids, another trait thought to be specific for the archaea, also occur in bacteria [27-31]. However, no bacteria are known to produce membrane lipids based on isoprenoidal side chains or possessing the 'archaeal' G1P stereochemistry. Third, some studies have reported that some archaea produce phospholipid fatty acids (e.g., [32]) but this may be due to contamination of the growth media [33]. Nevertheless, an almost complete biosynthetic pathway for fatty acid synthesis is encoded by many archaeal genomes [34]. Last, two uncultured archaeal groups, the Euryarchaeota Marine Group II (currently known as Candidatus Poseidoniales ord. nov. [35]) and Lokiarchaeota of the Asgard superphylum, contain archaeal lipid biosynthesis genes alongside bacterial-like fatty acid and ester-bond formation genes, but seem to lack the capacity to synthesize the G1P backbone via glycerol-1-P-dehydrogenase (G1PDH), while they do have the genetic ability to produce G3P [36]. This observation is exciting as the Asgard archaea are currently considered as the closest descendants of the archaeal ancestor leading to eukaryotes [37]. However, a recent phylogenomic study of the orthologs of bacterial lipid genes present in Asgard archaea does not provide compelling support for an origin of eukaryotic lipids via an archaeal host cell [38]. Moreover, there is no further evidence to date that the presence of these genes in those two archaeal groups actually leads to the synthesis of 'mixed membranes', i.e., membranes containing both 'bacterial' fatty acid ester-linked lipids and 'archaeal' isoprenoid ether-linked lipids, either heterochiral (containing G1P and G3P) or homochiral. Taken together, these observations expose a 'lipid divide' that is not as clearcut as originally thought. Nonetheless, no natural microbial representatives have ever been reported to synthesize 'mixed membranes'.

Here, we present the discovery of living bacteria of the phylum Candidatus Cloacimonetes of the Fibrobacteres-Chlorobi-Bacteroidetes (FCB) group superphylum, which are highly abundant in the deep anoxic waters of the Black Sea, harboring a putative 'mixed archaeal/bacterial membrane'. We observed that the metagenome-assembled genomes (MAGs) of this bacterial phylum contain the genes of the canonical bacterial fatty acid biosynthetic pathway but also, unexpectedly, homologs of key enzymes for archaeal membrane lipid biosynthesis. We validated the presence of these protein-coding genes both in silico and experimentally, and observed that they were expressed in the environment. Expression of these genes in Escherichia coli leads to the formation of a membrane containing ether-linked isoprenoid phospholipids. We hypothesize that the 'archaeal' membrane lipids of $\mathrm{Ca}$. Cloacimonetes have the G1P stereochemistry, awaiting validation based on isolation of these elusive bacteria and analysis of their membrane lipids. Database searches revealed the presence of the key archaeal membrane lipid biosynthetic genes not only in other $\mathrm{Ca}$. Cloacimonetes genomes, but also in other genomes of the FCB group superphylum and related candidate phyla, indicating that the ability to produce 'mixed membranes' might be widespread in the tree of life.

\section{Materials and methods}

\section{Oceanographic sampling}

All cruises in the Black Sea western gyre were performed with the R/V Pelagia. Suspended particulate matter (SPM) 
from 15 depths across the water column (50-2000 m) was collected at sampling station $2\left(\mathrm{~N} 42^{\circ} 53.8^{\prime}, \mathrm{E} 30^{\circ} 40.7^{\prime}\right.$, $2107 \mathrm{~m}$ depth) during the Phoxy cruise 64PE371 (BS2013) on 9-10 June 2013 (Table S1). At the same station, SPM was also collected from 1000, 1500, and 1980-m depth during the NESSC cruise 64PE408 (BS2016) on 31 January-2 February 2016, and from $2000 \mathrm{~m}$ depth during the 64PE444 cruise (BS2018) on 17 August 2018. SPM from four depths $(500,1000,1500$, and $2000 \mathrm{~m})$ was collected at sampling station $4\left(\mathrm{~N} 42^{\circ} 46.9^{\prime}\right.$, E29 $21.1^{\prime}, 2100 \mathrm{~m}$ depth) during the 64PE418 cruise (BS2017) on 27 March-5 April 2017. For the BS2013 and BS2017 cruises, SPM was collected with McLane WTS-LV in situ pumps (McLane Laboratories Inc., Falmouth) on pre-combusted glass fiber filters with $142-\mathrm{mm}$ diameter and 0.7 and $0.3-\mu \mathrm{m}$ pore size, respectively. For the BS2016 and BS28018 cruises, SPM was collected on $0.22 \mu \mathrm{m}$ Sterivex cartridge filters (Millipore). In all cases, all samples were stored at $-80^{\circ} \mathrm{C}$ until nucleic acid or lipid extraction (only for the glass fiber filters) was performed. Water samples were collected during the BS2018 cruise to attempt enrichment cultures and for visualization of the cell morphology as specified in the Supplementary Information.

\section{Lipid analysis environmental samples}

Total lipids were extracted from freeze-dried glass fiber filters as described in [39]. The Bligh and Dyer lipid extracts are expected to contain archaeal intact polar lipids (IPLs), which are composed of the core lipid (CL) attached to one or two polar head groups [40]. The Bligh and Dyer extracts were both analyzed directly for the presence of total archaeal CL, and also after acid hydrolysis to remove the polar head groups and quantify both the archaeal CLs and the IPL-derived CLs. Subtracting CLs from CL + IPLderived CLs allows for determination of the IPL-derived CLs linked to living archaeal biomass. Acid hydrolysis was performed in nitrogen-dried Bligh and Dyer extracts [41]. Extracts were analyzed by UHPLC-atmospheric pressure chemical ionization MS for archaeol and GDGTs, according to Hopmans et al. [42] with some modifications. Briefly, analysis was performed on an Agilent 1260 UHPLC coupled to a 6130 quadrupole MSD in selected ion monitoring mode. Separation was achieved on two UHPLC silica columns (BEH HILIC columns, $2.1 \times 150 \mathrm{~mm}, 1.7 \mu \mathrm{m}$; Waters) in series, fitted with a $2.1 \times 5 \mathrm{~mm}$ pre-column of the same material (Waters) and maintained at $30{ }^{\circ} \mathrm{C}$. Archaeol and GDGTs were eluted isocratically for $10 \mathrm{~min}$ with $10 \%$ $\mathrm{B}$, followed by a linear gradient to $18 \% \mathrm{~B}$ in $20 \mathrm{~min}$, then a linear gradient to $100 \% \mathrm{~B}$ in $20 \mathrm{~min}$, where $\mathrm{A}$ is hexane and $\mathrm{B}$ is hexane: isopropanol $(9: 1)$. Flow rate was $0.2 \mathrm{ml} \mathrm{min}^{-1}$. Total run time is $61 \mathrm{~min}$ with a $20 \mathrm{~min}$ re-equilibration. Source settings were identical to Schouten et al. [43].
Typical injection volume was $10 \mu \mathrm{l}$ of a $1 \mathrm{mg} \mathrm{ml}^{-1}$ solution. The $\mathrm{m} / \mathrm{z}$ values of the protonated molecules of archaeol and isoprenoid GDGTs were monitored. Archaeol and GDGTs were quantified by adding a $\mathrm{C}_{46}$ GTGT internal standard by using an archaeol:GDGT-0 standard (1:1) to correct for response differences between archaeol and GDGTs [44].

\section{Nucleic acid extraction and 16S rRNA gene amplicon sequencing}

DNA and RNA were extracted from sections of the glass fiber filters (1/8 filter from 50 to 130 -m depth and $1 / 4$ from 170 to 2000-m depth) or from the Sterivex filter cartridge with the RNA PowerSoil ${ }^{\circ}$ Total Isolation Kit plus the DNA elution accessory (Mo Bio Laboratories, Carlsbad, CA). RNA extracts were treated with DNAse and reversetranscribed to cDNA using random nonamers as described previously [45]. The 16S rRNA gene amplicon sequencing and analysis was performed as described previously [46] (see Table S2 and Supplementary Information for details). Taxonomy of the reads was assigned based on blast [47] and the SILVA database version 123 [48].

\section{Metagenome sequencing and assembly}

Unamplified DNA extracts from the 15 SPM samples of BS2013 were used to prepare TruSeq nano libraries which were further sequenced with Illumina Miseq (5 samples multiplexed per lane) at Utrecht Sequencing Facility, generating 45 million $2 \times 251 \mathrm{bp}$ paired-end reads. Quality control was performed with FastQC v0.11.3 (https://www. bioinformatics.babraham.ac.uk/projects/fastqc/) and reads with uncalled bases and remaining TruSeq adapters were removed with Flexbar v2.5 [49], keeping the longer side of the read with the '--ae any' flag. All reads were crossassembled with SPAdes v3.8.0 in '--meta' mode [50], with read error correction turned on. BWA-MEM v0.7.12-r1039 [51] was used to map the forward and reverse reads from individual samples to the cross-assembled scaffolds.

\section{Scaffold binning and assessment of MAG quality}

Scaffolds were binned into draft genome sequences based on coverage profile across samples and tetra-nucleotide frequency with MetaBAT v0.32.4 [52]. The '--superspecific' preset was used to minimize contamination. To increase sensitivity without losing specificity, MetaBAT was run with ensemble binning, which aims to combine highly similar bins ('-B' and '--pB' were set to $20 \%$ and $50 \%$, respectively). Quality of the MAGs was assessed based on absence and presence of lineage-specific marker gene sets after genome placement in a reference tree with CheckM v1.0.7 [53] in '--lineage_wf' mode. 


\section{Genome annotation and abundance estimation}

MAGs were annotated with Prokka v1.11 [54] in "--metagenome' mode. GenBank output files generated by Prokka were also annotated with the Rapid annotation using subsystem technology pipeline v2.0 [55]. The geranylgeranylglyceryl phosphate (GGGP) synthase of NIOZ-UU2 is only partially predicted by Prokka as it bridges a scaffold boundary (see Supplementary Information). For the homology searches and tree constructions detailed below a longer protein was reconstructed by concatenating the predicted partial protein sequence with the last part of the translated linked scaffold.

MAG abundance was estimated from the shotgun metagenomics data by generating depth files per sample for all the scaffolds with SAMtools v.1.3.1 [56], using the mpileup utility with flags '-aa' and '-A' (count orphans) set. Average read coverage per nucleobase of a scaffold was calculated by dividing the sum of depth of all positions by the length of the scaffold with N's removed. Coverage of a MAG was calculated likewise after concatenating the depth files of the scaffolds in that MAG. Average read coverage per nucleobase was normalized across samples by dividing by the total number of reads after quality control in the sample times $1,000,000$. Normalized data is only shown in Fig. 1.

\section{Manual cleaning of the MAGs}

The four $\mathrm{Ca}$. Cloacimonetes MAGs were cleaned by plotting coverage across samples for all the scaffolds in the MAG, and manually removing those scaffolds that did not clearly have the same coverage profile as the majority (see Supplementary Information for details). NIOZ-UU3 appeared clean based on its coverage profile so none of its scaffolds were removed. Because the removed scaffolds do not contain marker genes, completeness and contamination estimates did not change (see Table S3 for extended CheckM results of the four MAGs). Genome annotations and abundance estimations of MAGs were newly generated as described above after cleaning.

\section{Placement of MAGs in the FCB group superphylum tree}

To further check the phylogenetic affiliation of the four MAGs in comparison with close relatives, Bacteroidetes/ Chlorobi group genomes were downloaded from RefSeq [57], and other FCB group genomes from GenBank [58], both on February 8, 2017 (Table S4). For Ignavibacteriae and Chlorobi all the RefSeq representative genomes were downloaded, and for Bacteroidetes only the first ten representative genomes. We only included genomes that were estimated to be less than $10 \%$ contaminated by CheckM in '--lineage_wf mode', and that contained at least 4 out of 43 phylogenetically informative marker genes in single copy that CheckM uses for bin placement [53] (Table S4). We realigned the 43 marker genes individually with Clustal Omega v1.2.3 [59]. The genes were concatenated, gaps included if a gene was not present, and identical sequences collapsed (Table S4). A maximum likelihood tree was inferred with IQ-TREE v1.6.3 [60]. Model selection of nuclear models was performed with ModelFinder [61] and the best-fit model $(\mathrm{LG}+\mathrm{R} 8)$ chosen according to Bayesian Information Criterion. Branch support was based on 1000 ultrafast bootstraps [62]. The tree was visualized in iTOL [63].

We identified 16S rRNA genes in the FCB group genomes included in the tree with the CheckM 'ssu_finder' utility. 16S rRNA gene sequences were found in $21 \mathrm{Ca}$. Cloacimonetes genomes, including one of the MAGs (NIOZ-UU1) (Table S4). We aligned these sequences with the $\mathrm{Ca}$. Cloacimonetes 16S rRNA gene amplicon sequences using MAFFT v7.394 [64], sliced out the amplicon region from the genome sequences, and removed identical sequences (Table S4).

\section{Homology searches of GGGP synthase and (S)-2,3- di-0-geranylgeranylglyceryl phosphate (DGGGP) synthase in the Black Sea water column}

Predicted GGGP and DGGGP synthases from the four MAGs were queried with tblastn v2.6.0+ [47, 65] (e-value $<1 e^{-5}$ and $\geq 70 \%$ query coverage) against all scaffolds in the assembly. For the scaffolds with significant hits (61 for GGGP synthase and 43 for DGGGP synthase), we extracted the aligned part of the subject sequence of the best hit based on $e$-value on each scaffold. In addition to the queries we included a set of known GGGP and DGGGP synthases based on biochemical evidence and phylogenetic analyses [66], as well as other non-DGGGP prenyltransferases as 'outgroups' (see Supplementary Information). We also queried the GGGP and DGGGP synthases from the four MAGs against the NCBI nonredundant protein database (nr) [67] with blastp [47], and added the four best hits for each gene, all of which were found in $\mathrm{Ca}$. Cloacimonetes.

The protein sequences were aligned with MAFFT v7.394 [64], using a maximum number of 1000 iterative refinements and local pair alignment (L-INS-i). The sequence alignments were trimmed with trimAl v1.4.rev22 [68] in '-gappyout' mode, and identical sequences were collapsed. Final alignment lengths were 171 and 200 positions for GGGP synthase and DGGGP synthase, respectively. Maximum likelihood trees were inferred with IQ-TREE. Model selection of nuclear models was performed with ModelFinder and the best-fit model (LG + R7 for GGGP 


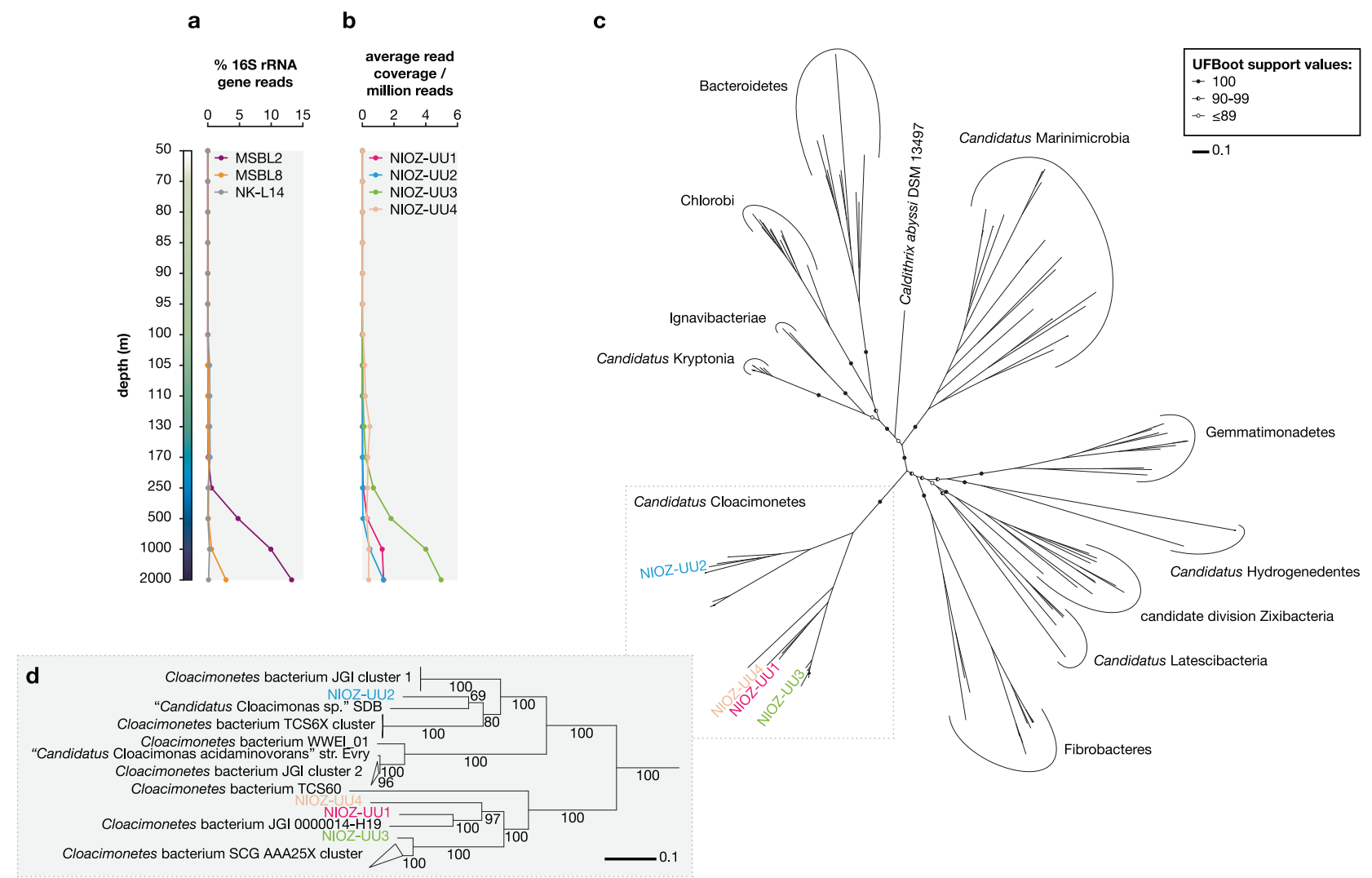

Fig. 1 Distribution within the Black Sea water column and phylogeny of $\boldsymbol{C a}$. Cloacimonetes. a Percentage of 16S rRNA gene reads attributed to different $\mathrm{Ca}$. Cloacimonetes groups during BS2013. b Estimated abundance of the four $\mathrm{Ca}$. Cloacimonetes MAGs. c Maximum likelihood phylogenetic tree of the FCB group superphylum based on 43 concatenated core genes. Circles along branches

synthase and $\mathrm{LG}+\mathrm{F}+\mathrm{R} 7$ for DGGGP synthase) chosen according to Bayesian Information Criterion. Branch support was based on 1000 ultrafast bootstraps. Trees were visualized in iTOL.

Taxonomy was assigned to hits based on taxonomic classification of the scaffolds on which they were found with Contig Annotation Tool v5.1.2 [69]. Database files were constructed on March 4, 2020. We used Prodigal v2.6.3 [70] for gene prediction and DIAMOND v0.9.21 [71] for protein alignment to $\mathrm{nr}$. The $f$ parameter was set to 0.3 to allow for speculative classifications. One scaffold had multiple classifications, and we chose the lowest classification that reached a majority vote based on bit-score support in this case.

\section{Homology searches of GGGP synthase and DGGGP synthase across the tree of life}

Predicted GGGP and DGGGP synthases from the four MAGs were queried with blastp v2.6.0+ $[47,65]$ against 110,421 annotated genomes available in the PATRIC genome database [72] on November 29, 2017. Blastp was run indicate ultrafast bootstrap approximation support values, with only values for deepest nodes shown. $\mathbf{d}$ Zoom in on the $\mathrm{Ca}$. Cloacimonetes phylogeny. Numbers along branches indicate ultrafast bootstrap approximation support values. Scale bars in c, d represent mean number of substitutions per site.

per genome ( $e$-value $<1 e-10$ and $\geq 70 \%$ query coverage) with a fixed database size of 20,000,000 to make $e$-values comparable across genomes. For GGGP synthase, we collected all hits and included the entire protein in the analysis. For DGGGP synthase, we only included hits that were annotated as 'Digeranylgeranylglyceryl phosphate synthase (EC 2.5.1.42)', and ('similar to') '(S)-2,3-di-O-geranylgeranylglyceryl phosphate synthase', and hypothetical proteins with $\geq 90 \%$ query coverage, to exclude other prenyltransferases from the superfamily. Again, entire proteins were included in the analysis. We added the queries, and the set of extra sequences (see above): known GGGP and DGGGP synthases, outgroups, and four best hits for each gene from nr. Identical sequences were collapsed.

Alignment and tree inference were performed with MAFFT, trimAl, and IQ-TREE as described above. Final alignment lengths were 246 and 266 positions for GGGP synthase and DGGGP synthase, respectively. The best-fit models were $\mathrm{LG}+\mathrm{R} 10$ for GGGP synthase and $\mathrm{LG}+\mathrm{F}+$ R10 for DGGGP synthase. For both trees, the consensus tree had a higher likelihood than the maximum likelihood tree found. Major clade separations were comparable 
between the maximum likelihood and consensus tree for both genes. Consensus trees were visualized in iTOL.

\section{Co-localization of GGGP and DGGGP synthase in FCB group superphylum genomes}

Predicted GGGP and DGGGP synthases from the four $\mathrm{Ca}$. Cloacimonetes MAGs were queried with tblastn ( $e$-value $<1 e^{-5}$ and $\geq 70 \%$ query coverage) against all downloaded GenBank/RefSeq FCB group superphylum genomes (see above) to identify homologs. If hits were located on the same scaffold, the minimum base pair distance between GGGP and DGGGP synthase homologs was considered as a measure of co-localization.

\section{Amplification, sequencing, gene expression, and quantification of specific genes in NIOZ-UU3}

To experimentally assess the assembly accuracy of NIOZUU3, primers were designed to amplify and sequence the region of the scaffold that contains the genes predicted to code for GGGP synthase, DGGGP synthase, polyprenyl synthase, and the bacterial marker gene predicted by CheckM (helicase PriA, see Supplementary Information) from the BS2013 2000-m depth sample. PCR reaction mixture was the following (final concentration): Q-solution (PCR additive) $1 \times$; PCR buffer $1 \times$; bovine serum albumin $\left(200 \mu \mathrm{g} \mathrm{ml}^{-1}\right)$; dNTPs $(40 \mu \mathrm{M})$; primers $(0.4 \mathrm{pmol}) ; \mathrm{MgCl}_{2}$ $(1.5 \mathrm{mM}) ; 2.5 \mathrm{U}$ Taq polymerase (Qiagen, Valencia, CA, USA). PCR conditions were the following: $95^{\circ} \mathrm{C}, 5 \mathrm{~min}$; $35 \times\left(95^{\circ} \mathrm{C}, 15 \mathrm{~s} ; 62^{\circ} \mathrm{C}\right.$ (melting temperature verified by gradient PCR), $30 \mathrm{~s} ; 72^{\circ} \mathrm{C}, 1 \mathrm{~min}$ per kilobase); final extension $72{ }^{\circ} \mathrm{C}, 5 \mathrm{~min}$. PCR product was gel purified (QIAquick gel purification kit, Qiagen), cloned in the TOPO-TA cloning ${ }^{\bullet}$ kit from Invitrogen (Carlsbad, CA, USA), and sequenced for verification. In addition, to determine the presence and expression of the GGGP synthase, DGGGP synthase, and polyprenyl synthase coding genes, PCRs targeting a fragment of the genes (see primers in Supplementary Information) were tested with DNA and cDNA from the SPM samples recovered at 1000 and 2000$\mathrm{m}$ depth from the Black Sea 2013 campaign as a template with the same PCR master mix as described above but with half amount of dNTPs and Taq Polymerase (melting temperature $62{ }^{\circ} \mathrm{C}$ verified by gradient PCR). Moreover, quantitative PCRs (qPCR) with the same specific primers targeting the GGGP and the DGGGP synthase coding genes were performed on DNA and cDNA extracts of the Black Sea 2013 campaign from 50 to 2000-m depth (15 samples). qPCR master mix was the same as used for amplifications above with the addition of Evagreen fluorescent nucleic acid dye $(0.625 \mathrm{nM}$ final concentration). PCR analyses were performed on a Bio-Rad CFX96 Real-Time System/C1000
Thermal cycler equipped with CFX Manager Software. Standard curves were generated by dilution of the verified amplicon of the GGGP and DGGGP synthase coding gene fragment obtained with DNA extracts of the SPM at 2000-m depth as described above.

\section{Construction of GGGPS and DGGGPS expression plasmids}

Plasmids for in vivo lipid production were constructed by PCR amplifying the GGGP synthase ORF from pLVA01 and the plasmid pRSFDuet-1 (Novagen) using the primers GGGPS-RSFDuet-F/R and RSFDuet-GGGPS-F/R, respectively, and further recombined [73] (Supplementary Information). A non-synonymous mutation (Met to Val, based on NIOZ-UU3) was corrected by site-directed mutagenesis using the primers GGGPS-SDM-F/R, resulting in pABW1. The DGGGP synthase ORF was amplified using the primers DGGGPS-F/R and cloned into pRSFDuet-1 using NcoI and BamHI to construct pABW2. pABW3 (encoding both GGGPS and DGGGPS) was constructed by re-amplifying DGGPS from pABW2 and cloning the amplicon as a NcoIBamHI fragment into pABW1. A N-terminally 6 His-tagged GGGP synthase overproduction plasmid (pABW4) was constructed by recombining [73] the GGGP synthase ORF from pABW1 and pET-28a(+) (Novagene) amplified using the primers GGGPS-ET28-F/R and ET28-GGGPS-F/R, respectively. All inserts were verified to encode correct proteins by sequencing.

\section{Recombinant production, purification, and in vitro enzyme assay of GGGP synthase}

Purification and enzymatic assay of the NIOZ-UU3 GGGP synthase was based on the method of Jain et al. [74]. E. coli BL21(DE3) harboring pABW4 was cultured in $250 \mathrm{ml}$ Lysogeny broth (LB) medium $\left(37^{\circ} \mathrm{C}, 200 \mathrm{rpm}\right)$ and induced with $0.5 \mathrm{mM}$ isopropyl $\beta$-D-1-thiogalactopyranoside (IPTG) at $0.6 \mathrm{OD}_{600 \mathrm{~nm}}$ for $4 \mathrm{~h}$. Cells were centrifuged (3500 rcf) and frozen. Subsequent steps were performed at room temperature, with samples and buffers kept on ice. Thawed cells were resuspended in $\sim 5 \mathrm{ml}$ lysis buffer $(50 \mathrm{mM}$ Tris$\mathrm{HCl} \mathrm{pH} 7.5,150 \mathrm{mM} \mathrm{NaCl}, 20 \mathrm{mM}$ imidazole, $1 \mathrm{mg} \mathrm{ml}^{-1}$ lysozyme), and a protease inhibitor (cOmplete ${ }^{\mathrm{TM}}$, EDTAfree; Roche, Basel) and sonicated to facilitate cell lysis. The lysate was cleared by centrifugation (20,000 rcf, $10 \mathrm{~min})$, glycerol was added (10\% final), and sample loaded onto a gravity column containing $1.5 \mathrm{ml}$ of nickel-nitrilotriacetic acid agarose beads (Qiagen, Venlo, NL) pre-equilibrated with protein buffer $(50 \mathrm{mM}$ Tris- $\mathrm{HCl} \mathrm{pH} 7.5,150 \mathrm{mM}$ $\mathrm{NaCl}, 20 \mathrm{mM}$ imidazole, $10 \%$ glycerol). Beads were washed with $\sim 30$ column volumes of protein buffer, and initially eluted by a titration of imidazole with GGGP 
synthase protein eluting at $200 \mathrm{mM}$. Subsequent elutions were performed with $250 \mathrm{mM}$ imidazole. The purity of the GGGP synthase protein was verified using $12 \% \mathrm{TGX}^{\mathrm{TM}}$ precast gels (Bio-Rad), stained with Bio-Safe ${ }^{\mathrm{TM}}$ Coomassie stain (Bio-Rad). The concentration of the purified protein was calculated based on the absorbance at $280 \mathrm{~nm}$ using a predicted extinction coefficient of $9002 \mathrm{M}^{-1} \mathrm{~cm}^{-1}$ (ExPASy ProtParam, averaged Cys reduced, and cysteine form).

Enzymatic activity of the purified $\mathrm{Ca}$. Cloacimonetes GGGP synthase was determined in an end-point assay using $0.1 \mu \mathrm{M}$ GGGP synthase, $10 \mathrm{mM}$ G1P or G3P and $100 \mu \mathrm{M}$ geranylgeranylpyrophosphate in a reaction buffer consisting of $50 \mathrm{mM}$ Tris- $\mathrm{HCl}$ ( $\mathrm{pH} 7.5$ ), $10 \mathrm{mM} \mathrm{MgCl}$, and carryover amounts of imidazole $(1 \mathrm{mM})$ and glycerol $(0.5 \%)$. Reactions were incubated for $2 \mathrm{~h}$ at $37^{\circ} \mathrm{C}$ in glass vials, extracted twice with $300 \mu \mathrm{L}$ n-butanol (water saturated), pooled and stored at $-20^{\circ} \mathrm{C}$. Analysis of the GGGP synthase enzyme assays were performed using ultra-high-pressure liquid chromatography-high resolution mass spectrometry (UHPLC-HRMS) based on Sturt et al. [40]. with some modifications as detailed below. Pooled butanol extracts were evaporated under a stream of nitrogen, redissolved in $50 \mu \mathrm{L}$ methanol:dichloromethane (1:1) and filtered $(0.45$ $\mu \mathrm{m}$, regenerated cellulose). Analysis was performed using an Agilent 1290 Infinity I UHPLC, equipped with thermostatted auto-injector and column oven, coupled to a $\mathrm{Q}$ Exactive Orbitrap MS with Ion Max source with heated electrospray ionization (HESI) probe (Thermo Fisher Scientific, Waltham, MA). Injection volume was $1 \mu$ (out of $50 \mu \mathrm{l})$. Separation was achieved on a YMC-Triart DiolHILIC column $(250 \times 2.0 \mathrm{~mm}, 1.9 \mu \mathrm{m}$ particles, pore size $12 \mathrm{~nm}$; YMC Co., Ltd, Kyoto, Japan) maintained at $30^{\circ} \mathrm{C}$. The following elution program was used with a flow rate of

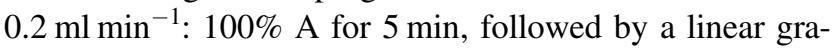
dient to $66 \%$ A: $34 \%$ B in $20 \mathrm{~min}$, maintained for $15 \mathrm{~min}$, followed by a linear gradient to $40 \% \mathrm{~A}: 60 \% \mathrm{~B}$ in $15 \mathrm{~min}$, followed by a linear gradient to $30 \% \mathrm{~A}: 70 \% \mathrm{~B}$ in $10 \mathrm{~min}$, where $\mathrm{A}=$ hexane/2-propanol/formic acid/14.8 $\mathrm{M} \mathrm{NH}_{3 \mathrm{aq}}$ (79:20:0.12:0.04 [volume in volume in volume in volume, $\mathrm{v} / \mathrm{v} / \mathrm{v} / \mathrm{v}]$ ) and $\mathrm{B}=2$-propanol/water/formic acid/14.8 M $\mathrm{NH}_{3 a q}$ (88:10:0.12:0.04 [v/v/v/v]). HESI settings were as follows: sheath gas $\left(\mathrm{N}_{2}\right)$ pressure 35 (arbitrary units), auxiliary gas $\left(\mathrm{N}_{2}\right)$ pressure 10 (arbitrary units), auxiliary gas (N2) T $50{ }^{\circ} \mathrm{C}$, sweep gas $\left(\mathrm{N}_{2}\right)$ pressure 10 (arbitrary units), spray voltage $4.0 \mathrm{kV}$ (positive ion ESI), capillary temperature $275^{\circ} \mathrm{C}$, S-Lens $70 \mathrm{~V}$. Lipids were analyzed with a mass range of $\mathrm{m} / \mathrm{z}, 350-2000$ (resolving power 70,000) followed by data dependent $\mathrm{MS}^{2}$ (resolving power 17,500), in which the ten most abundant masses in the mass spectrum (with the exclusion of isotope peaks) were fragmented successively (stepped normalized collision energy 15, 22.5, 30; isolation window $1.0 \mathrm{~m} / \mathrm{z}$ ). An inclusion list was used with a mass tolerance of $3 \mathrm{ppm}$, targeting the ammoniated molecule $\left[\mathrm{C}_{46} \mathrm{H}_{79} \mathrm{O}_{8} \mathrm{P}+\mathrm{NH}_{4}\right]^{+}$of GGGP at $\mathrm{m} / z$ 462.2979. The Q Exactive was calibrated within a mass accuracy range of 1 ppm using the Thermo Scientific Pierce LTQ Velos ESI Positive Ion Calibration Solution (containing a mixture of caffeine, MRFA, Ultramark 1621 , and $N$-butylamine in an acetonitrilemethanol-acetic solution). Identification of GGGP was aided by the analysis of 1-O-octadecyl-2-hydroxy-snglycero-3-phosphate $\left(\mathrm{C}_{18}\right.$-LPA; Avanti Polar Lipids, Inc. Alabama, USA), a structural analog of GGGP, which has a $\mathrm{C}_{18}$ carbon chain attached to the glycerol backbone instead of the geranylgeranyl carbon chain present in GGGP. $\mathrm{C}_{18}$-LPA showed similar chromatographic and mass spectral behavior to GGGP.

\section{Co-expression of GGGP and DGGGP synthases in E. coli}

E. coli $\mathrm{C} 43(\mathrm{DE} 3)$ [75] harboring geranylgeranyl diphosphate (GGPP) synthase (crtE) and G1PDH (araM) on plasmid pMS148 [11] was used for expression of the GGGP and DGGGP synthases (encoded on plasmids pABW1, -2 and -3 ). Cells growing exponentially in LB medium were diluted into magnesium-supplemented terrific broth medium [76] (Mg-TB; $1.2 \%$ tryptone, $2.4 \%$ yeast extract, $0.4 \%$ glycerol, $2 \mathrm{mM} \quad \mathrm{MgSO}_{4}, 0.23 \% \quad \mathrm{KH}_{2} \mathrm{PO}_{4}$, and $1.25 \%$ $\mathrm{K}_{2} \mathrm{HPO}_{4}$ ) to $0.01 \mathrm{OD}_{600 \mathrm{~mm}}$ induced with $0.4 \mathrm{mM}$ IPTG and incubated at $37^{\circ} \mathrm{C}(200 \mathrm{rpm})$ for $16 \mathrm{~h}$. Cells $(10 \mathrm{ml}$ culture normalized to $1.9 \mathrm{OD}_{600 \mathrm{~nm}}$ ) were harvested by centrifugation (4000 rcf, $10 \mathrm{~min}$ ) and washed twice with $0.85 \% \mathrm{NaCl}$, lyophilized, and then stored at $-80^{\circ} \mathrm{C}$. Analysis for production of archaeal-like lipids in E. coli was performed by extracting IPLs by a modified Bligh-Dyer extraction [77] that was analyzed according to [29] with some modifications: lyophilized cells were extracted $3 \times$ with BDE solvent mixture (2:1:0.8) methanol:dichloromethane (DCM):potassium phosphate buffer $(50 \mathrm{mM}, \mathrm{pH} 7)$ aided by sonication and centrifugation. The extracts were pooled and solvent ratios adjusted to 1:1:0.9, vigorously mixed, centrifuged, and the lower DCM phase transferred. The upper fraction was re-extracted twice with DCM, and the pooled extract was evaporated under a stream of nitrogen and stored dry at $-20^{\circ} \mathrm{C}$ until analysis. For analysis, samples were dissolved in $200 \mu \mathrm{l}$ hexane:isopropanol: $\mathrm{H}_{2} \mathrm{O}(718: 271: 10)$ and filtered $(0.45 \mu \mathrm{m})$, regenerated cellulose. Analysis was performed on an Agilent 1200 series LC (Agilent, San Jose, CA), equipped with thermostatted auto-injector and column oven, coupled to a Thermo LTQ XL linear ion trap with Ion Max source with electrospray ionization (ESI) probe (Thermo Scientific, Waltham, MA), was used. Separation was achieved on a YMC-Pack-Diol-120-NP column (250x $2.1 \mu \mathrm{m}, 5 \mu \mathrm{m}$ particles; YMC Co., Ltd, Japan) maintained at $30^{\circ} \mathrm{C}$. Elution program and ESI settings are described in [29]. The lipid extract was analyzed by an MS routine 
where a positive ion scan (m/z 400-2000) was followed by a data dependent $\mathrm{MS}^{2}$ experiment where the base peak of the mass spectrum was fragmented (normalized collision energy (NCE) 25, isolation width 5.0, activation Q 0.175). This was followed by a data dependent $\mathrm{MS}^{3}$ experiment where the base peak of the $\mathrm{MS}^{2}$ spectrum was fragmented under identical fragmentation conditions. This process was repeated on the 2 nd -4 th most abundant ions of the initial mass spectrum.

\section{Results and discussion}

\section{An abundant bacterium in the anoxic water column of the Black Sea}

The microbial diversity in the water column of the Black Sea, a basin whose euxinic waters may resemble the ancient oceans [78], was determined by 16S rRNA gene amplicon sequencing (Tables S1 and S2). Remarkably, a group of bacteria attributed to $\mathrm{Ca}$. Cloacimonetes was very abundant (i.e., representing 5-20\% of the total bacterial plus archaeal $16 \mathrm{~S}$ rRNA gene reads) in the euxinic waters between 500 and 2000-m depth (Fig. 1a and Table S2). Catalyzed reporter deposition Fluorescence In Situ Hybridization (CARD-FISH) using a specific probe targeting $\mathrm{Ca}$. Cloacimonetes confirmed their presence in the deep Black Sea waters (i.e., 2000-m depth) and identified the cell morphology of the $C a$. Cloacimonetes cells as oval to small rods (Fig. S1).

A genome-centric metagenomics approach was subsequently undertaken to shed light on the physiology of $\mathrm{Ca}$. Cloacimonetes; four draft genomes of this group with substantial to near completeness and low contamination were assembled (see Supplementary Information; Table S3). The high abundance of these MAGs in the deep waters matched the $\mathrm{Ca}$. Cloacimonetes 16S rRNA gene abundance profile (Fig. 1b). Phylogenomic analysis based on 43 concatenated core genes confirmed their taxonomic position (Fig. 1c, d and Fig. S2). Based on their genomic content, the predicted metabolism of the $\mathrm{Ca}$. Cloacimonetes found in the Black Sea is compatible with polysaccharide hydrolysis and fermentation of sugars and amino acids under an anaerobic or microaerophilic lifestyle (see Supplementary Information). Based on this genomic information, six different growth media supplemented with cellulose, cellobiose, microbial cell lysate, and amino acid mix were tested to obtain an enrichment but cultivation of $\mathrm{Ca}$. Cloacimonetes was not achieved, possibly because culture conditions did not mimic the high hydrostatic pressure present in the deep Black Sea water column (see Supplementary Information for details).
An archaeal membrane lipid biosynthetic pathway encoded by the $\mathrm{Ca}$. Cloacimonetes genomes

The analysis of the MAGs revealed unexpected features in the lipid biosynthetic pathways of $\mathrm{Ca}$. Cloacimonetes. Genes encoding the canonical bacterial fatty acid biosynthetic pathway were detected, including the gene (gps) coding for glycerol-3-phosphate dehydrogenase (catalyzing the formation of G3P), the acyltransferases responsible for the esterification of fatty acids and G3P, as well as genes coding for enzymes involved in downstream reaction [79] (see Supplementary Information). Hence, $\mathrm{Ca}$. Cloacimonetes harbors the genes enabling the formation of a normal bacterial membrane (i.e., based on G3P-esterified fatty acids). Strikingly, however, putative key genes of the archaeal lipid biosynthetic pathway (Fig. S3) were also detected in all four $\mathrm{Ca}$. Cloacimonetes MAGs. The gene encoding GGGP synthase is co-localized (i.e., encoded in close proximity) with the gene encoding DGGGP synthase (Supplementary Information). Homology searches show that the two genes are found in other Bacteria and Archaea in the Black Sea water column as well (Figs. S4 and S5). These two presumed archaeal enzymes together mediate the formation of the two ether bonds between isoprenoid alcohols and G1P resulting in the production of unsaturated archaeol [1]. Distant homologs of both GGGP and DGGGP synthase genes have previously been reported in bacterial genomes, however, their presence has never been associated with the production of 'archaeal' lipids. Whereas GGGP synthase activity has been confirmed in only a few bacteria [80], DGGGP synthase belongs to a large superfamily of UbiA prenyltransferases with several different potential functions [34] and bacterial homologs are assumed to have a different function. Moreover, there has never been an indication for co-expression of the two genes in bacteria. We tested and rejected the possibility that the co-localized GGGP and DGGGP synthase homologs in the $\mathrm{Ca}$. Cloacimonetes MAGs could have been introduced by a methodological error, both by in silico analyses and by experimentally amplifying and resequencing one of the scaffolds containing these genes from the original Black Sea water (Supplementary Information, Figs. S6 and S7). The presence of $\mathrm{Ca}$. Cloacimonetes GGGP and DGGGP synthase gene transcripts in the Black Sea water column confirmed that they were also expressed in the environment (Supplementary Information, Figs. S8-S10). This resulted in the hypothesis that this bacterium uses the GGGP and DGGGP synthases actively and thus is capable of synthesizing archaeal-like membrane lipids.

Next, we set out to verify that the detected genes coding for putative GGGP and DGGGP synthase have the predicted activity leading to archaeal-like membrane lipids. Previous studies have determined that GGGP synthase 


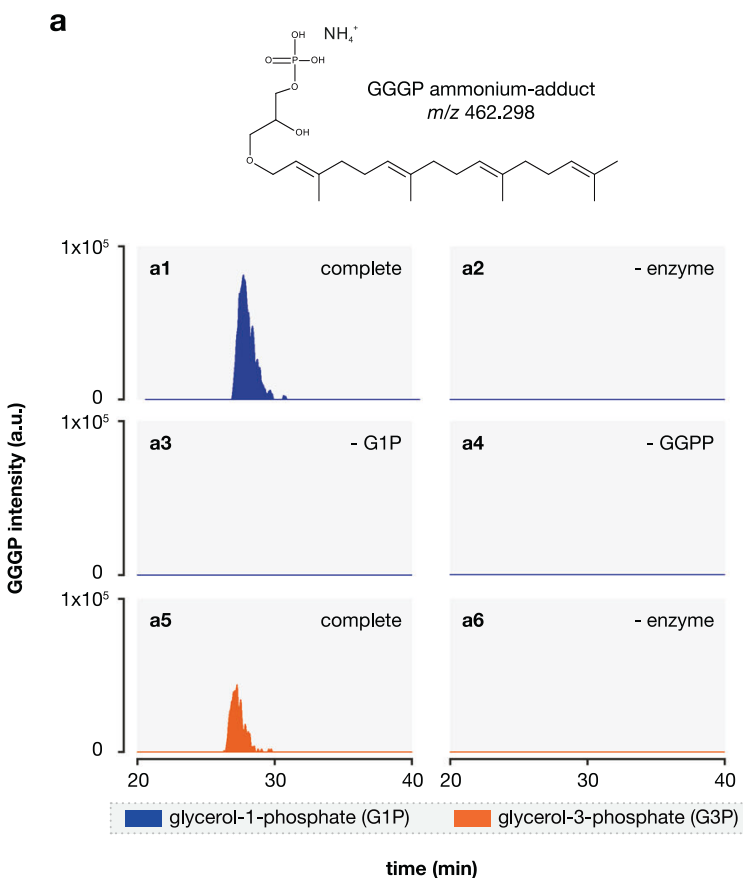

Fig. 2 Biochemical verification of $\mathbf{C a}$. Cloacimonetes GGGP and DGGGP synthase activities. a Enzyme assay of purified GGGP synthase with G1P (a1-a4) or G3P (a5 and a6). Extracted ion chromatogram, within $3 \mathrm{ppm}$ mass accuracy, of [GGGP $\left.+\mathrm{NH}_{4}\right]^{+}(\mathrm{m} / \mathrm{z}$ 462.298) of complete enzymatic assay (a1 and a5) or control assays lacking enzyme (a2 and a6), glycerol phosphate (a3) or geranylgeranyl-diphosphate, GGPP (a4). b Production of the lipid PG-archaeol with eight double

homologs of the phylum Bacteroidetes have in vitro GGGP synthase activity with G1P, like the archaeal GGGP synthase [80], rather than the heptaprenyl synthase activity of the bacterial PcrB orthologs detected in Bacillus subtilis [81]. To biochemically verify the predicted enzymatic activity in $\mathrm{Ca}$. Cloacimonetes, we recombinantly produced its GGGP synthase protein in E. coli. The purified protein was found to catalyze formation of GGGP from GGPP in an enzymatic assay (Fig. 2a; Supplementary Information, Figs. S11-S13), as expected in the archaeal membrane lipid biosynthetic pathway [1]. Then, we tested if the $\mathrm{Ca}$. Cloacimonetes GGGP and DGGGP synthases could support the formation of a 'mixed membrane' in a bacterial cell, by coexpressing them in an $E$. coli optimized for production of GGPP and G1P, the likely substrates of the two enzymes. Cells producing both GGGP and DGGGP synthase contained significant amounts of phosphatidylglycerol (PG) archaeol (i.e., archaeol, also known as diphytanyl glycerol diether) with PG as a polar head group with eight double bonds (Fig. 2b; Supplementary Information, Fig. S14), the expected intermediate in the biosynthesis of archaeal membrane lipids in the absence of a specific geranylgeranyl reductase in $E$. coli $[82,83]$. Hence, these experiments provide strong evidence for potential synthesis of etherlinked isoprenoid phospholipids by this group of bacteria.

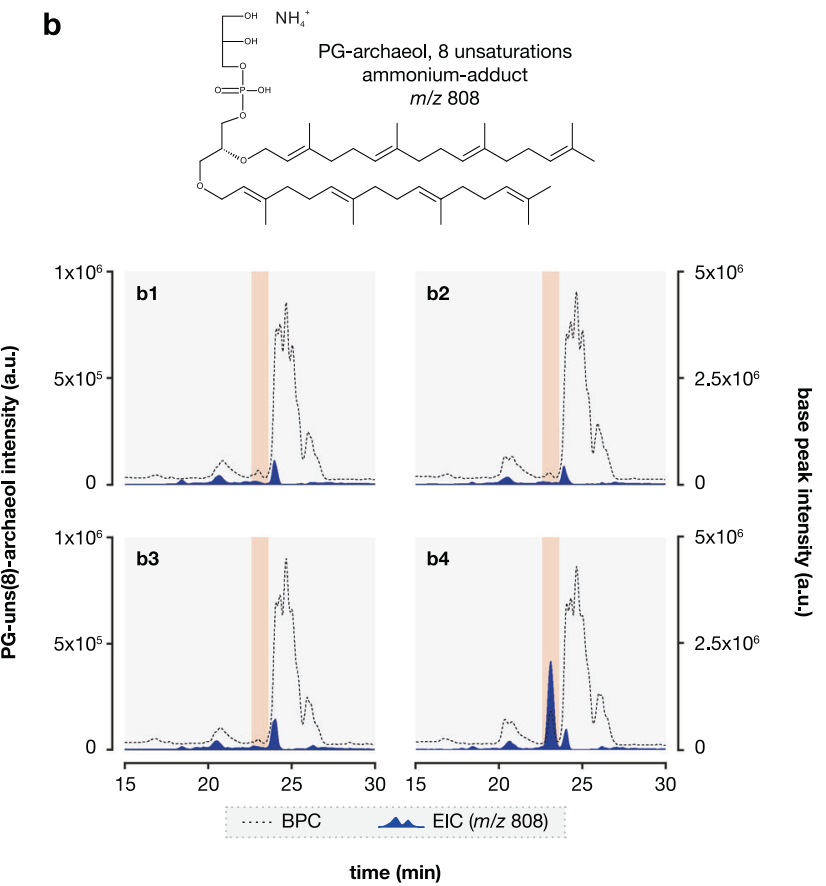

bonds or unsaturations (PG-unsat(8)-archaeol) in E. coli. Extracted ion chromatogram $( \pm 0.5$, mass units, mu $)$ of $[\text { PG-unsat }(8) \text {-archaeol }+\mathrm{H}]^{+}$ $(\mathrm{m} / \mathrm{z}, 808)$; (blue filled area, left axis) or base peak chromatogram (dotted line, right axis) of optimized E. coli containing empty-vector (b1) or vector encoding GGGP synthase (b2), DGGGP synthase (b3), or both GGGP and DGGGP synthases (b4). Orange boxes spans the retention time of PG-unsat(8)-archaeol.

\section{Additional lipid biosynthetic genes in the $\mathrm{Ca}$. Cloacimonetes MAGs}

In addition to genes for GGGP and DGGGP synthase, other genes required for the synthesis of isoprenoidal archaeal lipids (Fig. S3) were also detected in the $\mathrm{Ca}$. Cloacimonetes MAGs. They contain the genes for a complete bacterial isoprenoid MEP/DOXP pathway, genes coding for acetylCoA C-acetyltransferase and hydroxymethylglutaryl-CoA synthase of the Mevalonate pathway, and two polyprenyl synthases (see Supplementary Information, Fig. S15a), which support the existence of the biosynthetic pathway leading to GGPP, one of the substrates of GGGP synthase. Finally, the MAGs also encode geranylgeranyl reductases that are closely related to homologs found in Euryarchaeota (see Supplementary Information, Fig. S15b). Thus, in addition to ether bond formation (mediated by the putative GGGP and DGGGP synthases), these bacteria have the capacity to synthesize isoprenoid chains (via isoprenoid biosynthetic pathways and the presence of polyprenyl synthases) and saturate them (via the putative geranylgeranyl reductases), characteristics that are fully in line with archaeal lipid membrane biosynthesis [1].

Only two genes of the known lipid biosynthetic pathway in archaea were not detected in the $\mathrm{Ca}$. Cloacimonetes 


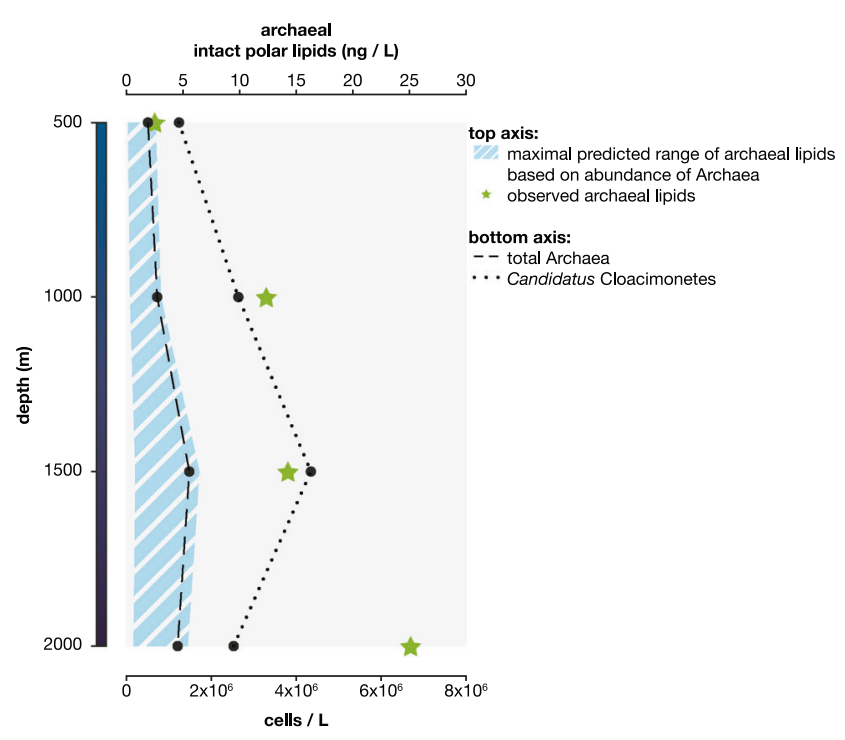

Fig. 3 Detected archaeal intact polar lipids (IPLs) in nanograms per liter (green stars) in the Black Sea water column, and predicted archaeal IPLs (shaded area) considering different estimates of membrane lipid production and cell size for the archaeal groups found. Total archaeal cells and $\mathrm{Ca}$. Cloacimonetes cells per liter based on qPCR and amplicon sequencing data are also indicated. All calculations are available in Supplementary File 1.

MAGs. One is the CDP-archaeol synthase (CarS) forming the activated CDP-archaeol before the addition of the polar head groups in combination with other specific archaeal enzymes [8]. However, it has been recently demonstrated that the bacterial CDP diacylglycerol synthase can replace the function of the archaeal CarS to generate CDP-archaeol [84]. Subsequently, substrate promiscuity allows the bacterial phosphatidylglycerophosphate synthetase together with the phosphatidylglycerophosphatase to recognize CDP-archaeol and synthesize archaetidylglycerol [84] as in the archaeal lipid biosynthetic pathway. All these bacterial enzymes are encoded by the four MAGs, which together with the biosynthetic genes mentioned above further support the formation of archaeal-like membrane lipids.

The second gene that is not detected in the four MAGs is the gene (egsA) coding for the enzyme enabling G1P biosynthesis (i.e., G1PDH). Its bacterial homolog (araM), occurring in a few bacteria [85], is also absent. This seems enigmatic at first sight, as it would suggest that the presumed archaeal membrane lipids synthesized by $\mathrm{Ca}$. Cloacimonetes do not have G1P as a glycerol phosphate backbone. Rather, they could have the G3P stereochemistry as promiscuity of GGGP synthase for G3P has been observed by others [11, 86, 87], as well as in our enzyme assay (Fig. 2a). However, it was recently demonstrated that an alternative pathway for the formation of G1P must exist within bacteria [11]. Notably, a genetically engineered bacterial strain of $E$. coli, whose genome contained archaeal lipid biosynthesis genes, formed archaeal membrane lipids with the G1P stereochemistry even when the araM coding gene was not included in the genetic construct. The genome did not contain egsA either. This shows that araM is not required for G1P synthesis in E. coli. This study also highlighted that in the presence of G3P as substrate, there is still a very high stereoselectivity towards G1P for the formation of archaeal membrane lipids. While we do not know how $E$. coli produces G1P, it is striking that the only known archaeal lipid biosynthesis gene that is missing in the $\mathrm{Ca}$. Cloacimonetes MAGs is nonessential for the formation of archaeal-like membrane lipids.

In summary, the four $\mathrm{Ca}$. Cloacimonetes MAGs encode a complete set of genes for the synthesis of ether-linked isoprenoid phospholipids. When archaeal GGGP and DGGGP synthase coding genes were previously expressed in $E$. coli, it formed a heterochiral membrane with G3Pbacterial lipids and G1P-archaeal lipids [11]. Given the strong stereoselectivity of the archaeal membrane lipid pathway for G1P and the observation that within bacteria an unknown G1P synthesis pathway exists, we hypothesize that $\mathrm{Ca}$. Cloacimonetes also forms ether-linked isoprenoid phospholipids with the G1P stereochemistry, which should be confirmed with the isolation and lipid analysis of members of this phylum.

The presence of the above-mentioned genes encoded by the $\mathrm{Ca}$. Cloacimonetes MAGs are compatible with the formation of archaeol (diether) lipid membranes. While many archaeal groups have been seen to synthesize also or exclusively tetraether membrane lipids (i.e., glycerol dibiphytanyl glycerol tetraethers, GDGTs; [88]), the genes required for their synthesis (i.e., potential GDGT synthase) remain unknown, thus we are unable to determine if the $\mathrm{Ca}$. Cloacimonetes MAGs could synthesize tetraether membrane lipids.

\section{Estimating the $\mathrm{Ca}$. Cloacimonetes contribution to the 'archaeal' membrane lipid pool in the Black Sea}

Next, we assessed whether the observed $\mathrm{Ca}$. Cloacimonetes abundances could significantly contribute to the 'archaeal' membrane lipids of living cells. In order to do so, archaeal IPLs (i.e., archaeol and GDGTs) were quantified in the Black Sea deep water column. IPLs are relatively easily hydrolyzed once the cell dies and therefore considered as biomarkers of living biomass [89].

We estimated the absolute abundance of archaeal IPLs, which showed an increase from 2.5 to $25 \mathrm{ng} \mathrm{L}^{-1}$ from 500 to 2000-m depth (Fig. 3). The archaeal population in the euxinic waters of the Black Sea mostly consists of Bathyarchaeota, DPANN archaea, and Euryarchaeota Thermoplasmatales, and ANME-1 (Table S2B, see also [39]). Based on their estimated cell numbers in the water column and their expected lipid content per cell we predict a maximum 

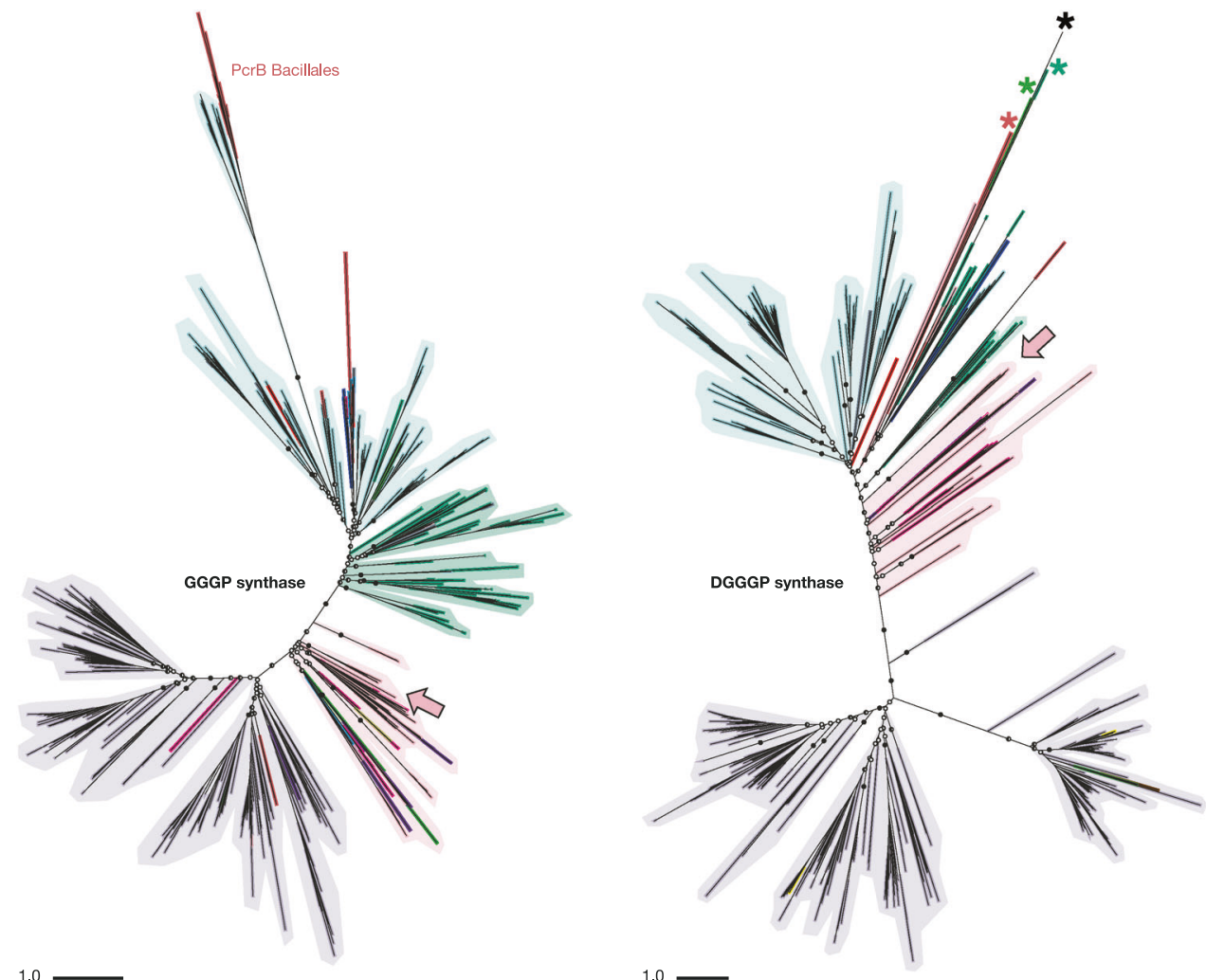

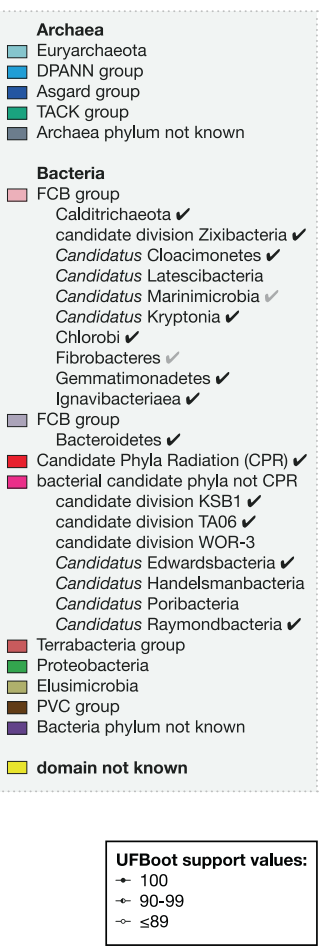

Fig. 4 Phylogenetic trees of the GGGP and DGGGP synthase homologs detected across the tree of life. Search for homologs was performed with $\mathrm{Ca}$. Cloacimonetes MAG sequences (arrows), in genomes from both cultures and environmental samples. Shadings illustrate the dominant group in the clade. Circles along branches indicate ultrafast bootstrap approximation support values, with only values for deepest nodes shown. See Fig. S6 and Fig. S7 for annotated trees with all branch support values. Scale bars represent mean number of substitutions per site. Asterisks in the DGGGP synthase tree indicate known UbiA prenyltransferases that do not have DGGGP synthase activity. A checkmark in the legend marks bacterial groups with genomes that code for both GGGP and DGGGP synthase, a gray checkmark marks groups in which both genes are found but not in the same genome. TACK includes the Thaumarchaeota and the Crenarchaeota. Archaeal or bacterial 'phylum not known': phylum is not known but the genome is annotated on a lower level, or sequence represents multiple groups. 'Domain not known': genomes for which no lineage was found on the PATRIC servers. archaeal membrane lipid concentration of $<6.5 \mathrm{ng} \mathrm{L}^{-1}$ (Fig. 3; Supplementary Information). At 1000-2000-m depth, this represents a striking offset between observed and expected archaeal IPL concentrations ranging at least from two- to fivefold. The mismatch between observed and expected is likely larger considering that these estimates represent an ideal case scenario (see Supplementary Information). The mismatch could be due to preservation of suspended IPLs in the anoxic waters of the Black Sea. Extracellular archaeal IPLs, especially those with more stable glycosidic bonds, could potentially be preserved as fossils as previously observed in deep anoxic sediments (e.g., [90]). However, this possibility seems unlikely, as the IPLs are detected in the water column, which is a more dynamic system than sediments. Moreover, most of the archaeal IPLs detected in the Black Sea do not have glycosidic-based polar head groups but the more labile PG, phosphatidylserine, or phosphatidylethanolamine head groups [39]. Therefore, the mismatch is more likely explained by production of archaeal-like ether-linked isoprenoid membrane lipids by the highly abundant $\mathrm{Ca}$.
Cloacimonetes bacteria. It is currently not possible to determine the stereochemistry of the archaeal IPLs detected in environmental samples as the analysis would require much higher concentrations of purified archaeal lipids. Hence, although experimental confirmation of archaeal IPL synthesis by $\mathrm{Ca}$. Cloacimonetes bacteria and the stereochemistry of these lipids await their isolation, these environmental observations provide enticing circumstantial evidence for the bacterial production of archaeallike membrane lipids.

\section{Archaeal lipid biosynthetic genes in Ca. Cloacimonetes and other bacteria}

Homology searches coupled to phylogenetic analyses indicated that the presence of archaeal lipid biosynthetic genes in bacterial genomes is not limited to $\mathrm{Ca}$. Cloacimonetes from the Black Sea. Close GGGP and DGGGP synthase homologs are found together in other genomes of $\mathrm{Ca}$. Cloacimonetes, as well as in other FCB group 
superphylum bacteria, related bacterial candidate phyla, and in a genome of $\mathrm{Ca}$. Parcubacteria of the Candidate Phyla Radiation [91] (Fig. 4; Figs. S16-S18, Supplementary Information). The phylogenetic topologies of both the GGGP and DGGGP synthases in bacteria are similar with respect to both branching of bacterial groups and in sharing a close affiliation with GGGP and DGGGP synthases from the archaeal TACK group, in particular Crenarchaeota [34], suggesting that the two genes share a similar evolutionary history (Fig. 4; Figs. S16 and S17, Supplementary Information). Co-localization of GGGP synthase and DGGGP synthase as observed in the four $\mathrm{Ca}$. Cloacimonetes MAGs has previously only been seen in some Euryarchaeota, and within bacteria seems to be restricted to $\mathrm{Ca}$. Cloacimonetes (Supplementary Information). Considering the basal placement of these genomes in the bacterial clade of both trees (Fig. 4, Figs. S16 and S17), we hypothesize that genomic co-localization of the genes is the ancestral state.

The extended presence and close phylogenetic associations of the GGGP and DGGGP synthase homologs in the FCB group superphylum and related candidate phyla strongly supports an origin in Bacteria before the radiation of the FCB group superphylum. This suggests that the capacity to synthesize 'mixed membranes' has been a trait of these bacteria for a long period in evolutionary history. Two evolutionary scenarios may explain our current observations. First, the contemporary presence of these enzymes in the FCB group superphylum bacteria could reflect an evolutionary remnant of the 'mixed membrane' stage after LUCA but before the diversification of Bacteria. Notably, a recent study that also evaluated the phylogeny of GGGP and DGGGP synthases using outgroup-free routing could not exclude a LUCA origin for both genes [38]. Second, if the ancestor of the FCB group superphylum contained a homochiral bacterial membrane like the other contemporary bacterial groups, the phylogenetic similarities of the co-localized genes could also reflect an ancient horizontal gene transfer (HGT) from an ancestral archaeal lineage into the FCB group ancestor (see Supplementary Information).

\section{Implications for the 'lipid divide'}

In contrast to the dogma of the 'lipid divide', bacteria of the FCB group superphylum harbor a complete archaeal-like membrane lipid biosynthetic pathway. Our data indicate that members of $\mathrm{Ca}$. Cloacimonetes have the potential to synthesize ether-linked isoprenoid phospholipids, possibly with the G1P stereochemistry, in which case they would possess a true heterochiral 'mixed membrane'. This is the first evidence of naturally occurring organisms with this ability. The presence of bacterial and archaeal lipid biosynthesis genes in $\mathrm{Ca}$. Cloacimonetes strikingly resembles the Marine Group II Euryarchaeota (currently known as Candidatus Poseidoniales ord. nov. [35]) [36] and some members of the Asgard superphylum, which harbor genes for the synthesis of putative bacterial membrane lipids (see Supplementary Information). The existence of a natural contemporary bacterial counterpart synthesizing archaeallike membranes might provide weight to the hypothesis that these archaeal groups also synthesize 'mixed membranes'. Hence, $\mathrm{Ca}$. Cloacimonetes, as well as the rest of the FCB group superphylum, appear to be key in our understanding of the 'lipid divide'. Their membranes may possibly reflect evolutionary remnants of the hypothetical 'mixed membrane' of LUCA, or an ancient HGT. In either case, this discovery provides further support for the existence and potential feasibility of 'mixed membranes' in natural environments and over a long period in evolutionary history, bridging the lipid divide.

\section{Data availability}

The 16S rRNA gene amplicon reads (raw data) have been deposited in the NCBI Sequence Read Archive (SRA) under BioProject ID PRJNA423140, PRJNA649254-57. The $\mathrm{Ca}$. Cloacimonetes MAGs are deposited in IMG under the following IMG accession IDs: 134200 (NIOZ-UU1), 134201 (NIOZ-UU2), 134202 (NIOZ-UU3), 151202 (NIOZ-UU4). The 15 metagenomes (raw data), assembly, and MAGs generated in this study are available under BioProject ID PRJNA649215.

Acknowledgements We thank Melvin Siliakus for providing several of the plasmid constructs and for useful suggestions to improve the manuscript. We are also thankful to Julian Vosseberg, John van Dam, Anja Spang, and Jan de Leeuw for suggestions and constructive discussions. We acknowledge the Utrecht Sequencing Facility (USF), which is partially subsidized by the Hubrecht Institute, Utrecht University, and UMC Utrecht, for the sequencing data and service. We thank Jan Kees van Amerongen, Elda Panoto, Maartje Brouwer, Michele Grego, and Michel Koenen for providing technical support. We acknowledge the crew and scientists of the R/V Pelagia cruises 64PE371 (chief scientist Gert-Jan Reichart) and 64PE408 (chief scientist Marcel van der Meer). JSSD received funding from the European Research Council (ERC) under the European Union's Horizon 2020 research and innovation program (grant agreement no 694569-MICROLIPIDS). LV and JSSD receive funding from the Soehngen Institute for Anaerobic Microbiology (SIAM) through a Gravitation Grant (024.002.002) from the Dutch Ministry of Education, Culture and Science (OCW). BED is supported by the Netherlands Organization for Scientific Research (NWO) Vidi grant 864.14.004. FABvM and BED are supported by ERC Consolidator grant 865694 .

Author contributions LV, BED, and JSSD conceived the study. LV, FABvM, and BED analyzed environmental sequencing data and performed phylogenetic analyses. ABW performed studies of the recombinant proteins. SY performed CARD-FISH and enrichment experiments. $\mathrm{ABW}$ and $\mathrm{ECH}$ analyzed enzymatic assays and cells 
using LC-MS. LV, FABvM, and JSSD wrote, and all authors edited and approved the manuscript.

\section{Compliance with ethical standards}

Conflict of interest The authors declare that they have no conflict of interest.

Publisher's note Springer Nature remains neutral with regard to jurisdictional claims in published maps and institutional affiliations.

Open Access This article is licensed under a Creative Commons Attribution 4.0 International License, which permits use, sharing, adaptation, distribution and reproduction in any medium or format, as long as you give appropriate credit to the original author(s) and the source, provide a link to the Creative Commons license, and indicate if changes were made. The images or other third party material in this article are included in the article's Creative Commons license, unless indicated otherwise in a credit line to the material. If material is not included in the article's Creative Commons license and your intended use is not permitted by statutory regulation or exceeds the permitted use, you will need to obtain permission directly from the copyright holder. To view a copy of this license, visit http://creativecommons. org/licenses/by/4.0/.

\section{References}

1. Koga Y, Morii H. Biosynthesis of ether-type polar lipids in Archaea and evolutionary considerations. Microbiol Mol Biol R. 2007;71:97-120.

2. Koga Y, Kyuragi T, Nishihara M, Sone N. Did archaeal and bacterial cells arise independently from noncellular precursors? A hypothesis stating that the advent of membrane phospholipid with enantiomeric glycerophosphate backbones caused the separation of the two lines of descent. J Mol Evol. 1998;47:631-631.

3. Martin W, Russell MJ. On the origins of cells: a hypothesis for the evolutionary transitions from abiotic geochemistry to chemoautotrophic prokaryotes, and from prokaryotes to nucleated cells. Philos Trans R Soc Lond Ser B Biol Sci. 2003;358:59-85.

4. Koonin EV, Martin W. On the origin of genomes and cells within inorganic compartments. Trends Genet. 2005;21:647-54.

5. Sojo V, Pomiankowski A, Lane N. A bioenergetic basis for membrane divergence in Archaea and bacteria. Plos Biol. 2014;12:e1001926.

6. Lombard J, López-García P, Moreira D. The early evolution of lipid membranes and the three domains of life. Nat Rev Microbiol. 2012;10:507-15.

7. Peretó J, López-García P, Moreira D. Ancestral lipid biosynthesis and early membrane evolution. Trends Biochem Sci. 2004;29:469-77.

8. Koga Y. Early evolution of membrane lipids: how did the lipid divide occur? J Mol Evol. 2011;72:274-82.

9. Wächtershäuser G. From pre-cells to Eukarya-a tale of two lipids. Mol Microbiol. 2003;47:13-22.

10. Shimada H, Yamagishi A. Stability of heterochiral hybrid membrane made of bacterial sn-G3P lipids and archaeal sn-G1P lipids. Biochem-us. 2011;50:4114-20.

11. Caforio A, Siliakus MF, Exterkate M, Jain S, Jumde VR, Andringa RLH, et al. Converting Escherichia coli into an archaebacterium with a hybrid heterochiral membrane. Proc Natl Acad Sci. 2018;115:3704-9.

12. López-García P, Moreira D. Open questions on the origin of eukaryotes. Trends Ecol Evol. 2015;30:697-708.
13. Eme L, Spang A, Lombard J, Stairs CW, Ettema TJG. Archaea and the origin of eukaryotes. Nat Rev Microbiol. 2017;15:711-23.

14. Martin W, Müller M. The hydrogen hypothesis for the first eukaryote. Nature. 1998;392:37-41.

15. Archibald JM. The eocyte hypothesis and the origin of eukaryotic cells. Proc Natl Acad Sci. 2008;105:20049-50.

16. Cox CJ, Foster PG, Hirt RP, Harris SR, Embley TM. The archaebacterial origin of eukaryotes. Proc Natl Acad Sci. 2008;105:20356-61.

17. Zaremba-Niedzwiedzka K, Caceres EF, Saw JH, Bäckström D, Juzokaite L, Vancaester E, et al. Asgard Archaea illuminate the origin of eukaryotic cellular complexity. Nature. 2017;541:353-8.

18. Moreira D, López-García P. Symbiosis between methanogenic Archaea and $\delta$-proteobacteria as the origin of eukaryotes: the syntrophic hypothesis. J Mol Evol. 1998;47:517-30.

19. López-García P, Moreira D. Selective forces for the origin of the eukaryotic nucleus. Bioessays. 2006;28:525-33.

20. López-García P, Moreira D. The Syntrophy hypothesis for the origin of eukaryotes revisited. Nat Microbiol. 2020;5:655-67.

21. Gould SB, Garg SG, Martin WF. Bacterial vesicle secretion and the evolutionary origin of the eukaryotic endomembrane system. Trends Microbiol. 2016;24:525-34.

22. Langworthy TA, Holzer G, Zeikus JG, Tornabene TG. Iso- and anteiso-branched glycerol diethers of the thermophilic anaerobe Thermodesulfotobacterium commune. Syst Appl Microbiol. 1983;4:1-17.

23. Huber R, Wilharm T, Huber D, Trincone A, Burggraf S, König H, et al. Aquifex pyrophilus gen. nov. sp. nov., represents a novel group of marine hyperthermophilic hydrogen-oxidizing bacteria. Syst Appl Microbiol. 1992;15:340-51.

24. Huber R, Rossnagel P, Woese CR, Rachel R, Langworthy TA, Stetter KO. Formation of ammonium from nitrate during chemolithoautotrophic growth of the extremely thermophilic bacterium ammonifex degensii gen. nov. sp. nov. Syst Appl Microbiol. 1996;19:40-9.

25. Rosa MD, Gambacorta A, Huber R, Lanzotti V, Nicolaus B, Stetter KO, et al. A new 15,16-dimethyl-30-glyceryloxytriacontanoic acid from lipids of Thermotoga maritima. J Chem Soc Chem Commun. 1988;0:1300.

26. Sinninghe Damsté JS, Strous M, WIC Rijpstra, Hopmans EC, Geenevasen JAJ, Duin ACTvan, et al. Linearly concatenated cyclobutane lipids form a dense bacterial membrane. Nature. 2002;419:708-12.

27. Sinninghe Damsté JS, Rijpstra WIC, Hopmans EC, Schouten S, Balk M, Stams AJM. Structural characterization of diabolic acidbased tetraester, tetraether and mixed ether/ester, membranespanning lipids of bacteria from the order Thermotogales. Arch Microbiol. 2007;188:629-41.

28. Weijers JWH, Schouten S, Hopmans EC, Geenevasen JAJ, David ORP, Coleman JM, et al. Membrane lipids of mesophilic anaerobic bacteria thriving in peats have typical archaeal traits. Environ Microbiol. 2006;8:648-57.

29. Sinninghe Damsté JS, Rijpstra WIC, Hopmans EC, Weijers JWH, Foesel BU, Overmann J, et al. 13,16-dimethyl octacosanedioic acid (iso-diabolic acid), a common membrane-spanning lipid of acidobacteria subdivisions 1 and 3. Appl Environ Micro. 2011;77:4147-54.

30. Sinninghe Damsté JS, Rijpstra WIC, Foesel BU, Huber KJ, Overmann J, Nakagawa S, et al. An overview of the occurrence of ether- and ester-linked iso-diabolic acid membrane lipids in microbial cultures of the Acidobacteria: implications for brGDGT paleoproxies for temperature and $\mathrm{pH}$. Org Geochem. 2018; 124:63-76.

31. Sinninghe Damsté JS, Rijpstra WIC, Strous M, Jetten MSM, David ORP, Geenevasen JAJ, et al. A mixed ladderane/n-alkyl 
glycerol diether membrane lipid in an anaerobic ammoniumoxidizing bacterium. Chem Commun. 2004;0:2590-1.

32. Gattinger A, Schloter M, Munch JC. Phospholipid etherlipid and phospholipid fatty acid fingerprints in selected euryarchaeotal monocultures for taxonomic profiling. Fems Microbiol Lett. 2002;213:133-9.

33. Dibrova DV, Galperin MY, Mulkidjanian AY. Phylogenomic reconstruction of Archaeal fatty acid metabolism. Environ Microbiol. 2014;16:907-18.

34. Lombard J, López-García P, Moreira D. Phylogenomic investigation of phospholipid synthesis in Archaea. Archaea 2012;2012:1-13.

35. Rinke C, Rubino F, Messer LF, Youssef N, Parks DH, Chuvochina $\mathrm{M}$, et al. A phylogenomic and ecological analysis of the globally abundant Marine Group II Archaea (Ca. Poseidoniales ord. nov.). Isme J. 2018;13:663-75.

36. Villanueva L, Schouten S, Sinninghe Damsté JS. Phylogenomic analysis of lipid biosynthetic genes of Archaea shed light on the 'lipid divide. Environ Microbiol. 2017;19:54-69.

37. Spang A, Saw JH, Jørgensen SL, Zaremba-Niedzwiedzka K, Martijn J, Lind AE, et al. Complex Archaea that bridge the gap between prokaryotes and eukaryotes. Nature. 2015;521:173-9.

38. Coleman GA, Pancost RD, Williams TA. Investigating the origins of membrane phospholipid biosynthesis genes using outgroup-free rooting. Genome Biol Evol. 2019;11:883-98.

39. Sollai M, Villanueva L, Hopmans EC, Reichart G-J, Sinninghe, Damsté JS. A combined lipidomic and 16S rRNA gene amplicon sequencing approach reveals archaeal sources of intact polar lipids in the stratified Black Sea water column. Geobiology. 2019;17:91-109.

40. Sturt HF, Summons RE, Smith K, Elvert M, Hinrichs K-U. Intact polar membrane lipids in prokaryotes and sediments deciphered by high-performance liquid chromatography/electrospray ionization multistage mass spectrometry-new biomarkers for biogeochemistry and microbial ecology. Rapid Commun mass Spectrom: RCM. 2004;18:617-28.

41. Buckles LK, Villanueva L, Weijers JWH, Verschuren D, Sinninghe Damsté JS. Linking isoprenoidal GDGT membrane lipid distributions with gene abundances of ammonia-oxidizing Thaumarchaeota and uncultured crenarchaeotal groups in the water column of a tropical lake (Lake Challa, East Africa). Environ Microbiol. 2013;15:2445-62.

42. Hopmans EC, Schouten S, Sinninghe Damsté JS. The effect of improved chromatography on GDGT-based palaeoproxies. Org Geochem. 2016;93:1-6.

43. Schouten S, Huguet C, Hopmans EC, Kienhuis MVM, Sinninghe, Damsté JS. Analytical methodology for TEX86 paleothermometry by high-performance liquid chromatography/atmospheric pressure chemical ionization-mass spectrometry. Anal Chem. 2007;79:2940-4.

44. Huguet C, Hopmans EC, Febo-Ayala W, Thompson DH, Sinninghe Damsté JS, Schouten S. An improved method to determine the absolute abundance of glycerol dibiphytanyl glycerol tetraether lipids. Org Geochem. 2006;37:1036-41.

45. Holmes DE, Nevin KP, Lovley DR. In situ expression of nifD in geobacteraceae in subsurface sediments. Appl Environ Micro. 2004;70:7251-9.

46. Moore EK, Villanueva L, Hopmans EC, Rijpstra WIC, Mets A, Dedysh SN, et al. Abundant trimethylornithine lipids and specific gene sequences are indicative of planctomycete importance at the oxic/anoxic interface in sphagnum-dominated northern wetlands. Appl Environ Micro. 2015;81:6333-44.

47. Altschul SF, Gish W, Miller W, Myers EW, Lipman DJ. Basic local alignment search tool. J Mol Biol. 1990;215:403-10.

48. Quast C, Pruesse E, Yilmaz P, Gerken J, Schweer T, Yarza P, et al. The SILVA ribosomal RNA gene database project: improved data processing and web-based tools. Nucleic Acids Res. 2013;41:D590-6.

49. Dodt M, Roehr J, Ahmed R, Dieterich C. FLEXBAR-flexible barcode and adapter processing for next-generation sequencing platforms. Biology. 2012;1:895-905.

50. Nurk S, Meleshko D, Korobeynikov A, Pevzner PA. metaSPAdes: a new versatile metagenomic assembler. Genome Res. 2017;27:824-34.

51. Li H. Aligning sequence reads, clone sequences and assembly contigs with BWA-MEM. 2013;16:q-bio.GN. https://arxiv.org/a bs/1303.3997.

52. Kang DD, Froula J, Egan R, Wang Z. MetaBAT, an efficient tool for accurately reconstructing single genomes from complex microbial communities. Peerj. 2015;3:e1165.

53. Parks DH, Imelfort M, Skennerton CT, Hugenholtz P, Tyson GW. CheckM: assessing the quality of microbial genomes recovered from isolates, single cells, and metagenomes. Genome Res. 2015;25:1043-55.

54. Seemann T. Prokka: rapid prokaryotic genome annotation. Bioinformatics. 2014;30:2068-9.

55. Aziz RK, Bartels D, Best AA, DeJongh M, Disz T, Edwards RA, et al. The RAST server: rapid annotations using subsystems technology. Bmc Genomics. 2008;9:75.

56. Li H, Handsaker B, Wysoker A, Fennell T, Ruan J, Homer N, et al. The Sequence Alignment/Map format and SAMtools. Bioinformatics 2009;25:2078-9.

57. Pruitt KD, Tatusova T, Maglott DR. NCBI reference sequences (RefSeq): a curated non-redundant sequence database of genomes, transcripts and proteins. Nucleic Acids Res. 2007;35:D61-5.

58. Benson DA, Cavanaugh M, Clark K, Karsch-Mizrachi I, Lipman DJ, Ostell J, et al. GenBank. Nucleic Acids Res. 2017;45: D37-42.

59. Sievers F, Wilm A, Dineen D, Gibson TJ, Karplus K, Li W, et al. Fast, scalable generation of high-quality protein multiple sequence alignments using Clustal Omega. Mol Syst Biol. 2011;7:539.

60. Nguyen L-T, Schmidt HA, Haeseler A, von, Minh BQ. IQ-TREE: a fast and effective stochastic algorithm for estimating maximumlikelihood phylogenies. Mol Biol Evol. 2015;32:268-74.

61. Kalyaanamoorthy S, Minh BQ, Wong TKF, Haeseler A, von, Jermiin LS. ModelFinder: fast model selection for accurate phylogenetic estimates. Nat Methods. 2017;14:587-9.

62. Hoang DT, Chernomor O, Haeseler A, von, Minh BQ, Vinh LS. UFBoot2: improving the ultrafast bootstrap approximation. Mol Biol Evol. 2018;35:518-22.

63. Letunic I, Bork P. Interactive tree of life (iTOL) v3: an online tool for the display and annotation of phylogenetic and other trees. Nucleic Acids Res. 2016;44:W242-5.

64. Katoh K, Standley DM. MAFFT Multiple Sequence Alignment Software Version 7: improvements in performance and usability. Mol Biol Evol. 2013;30:772-80.

65. Camacho C, Coulouris G, Avagyan V, Ma N, Papadopoulos J, Bealer K, et al. BLAST+: architecture and applications. Bmc Bioinforma. 2009;10:421.

66. Villanueva L, Sinninghe Damsté JS, Schouten S. A re-evaluation of the archaeal membrane lipid biosynthetic pathway. Nat Rev Microbiol. 2014;12:438-48.

67. Sayers EW, Agarwala R, Bolton EE, Brister JR, Canese K, Clark $\mathrm{K}$, et al. Database resources of the National Center for Biotechnology Information. Nucleic Acids Res. 2018;47:D23-8.

68. Capella-Gutierrez S, Silla-Martinez JM, Gabaldon T. trimAl: a tool for automated alignment trimming in large-scale phylogenetic analyses. Bioinformatics. 2009;25:1972-3.

69. von Meijenfeldt FAB, Arkhipova K, Cambuy DD, Coutinho FH, Dutilh BE. Robust taxonomic classification of uncharted microbial sequences and bins with CAT and BAT. Genome Biol. 2019;20:217. 
70. Hyatt D, Chen G-L, LoCascio PF, Land ML, Larimer FW, Hauser LJ. Prodigal: prokaryotic gene recognition and translation initiation site identification. Bmc Bioinforma. 2010;11:119.

71. Buchfink B, Xie C, Huson DH. Fast and sensitive protein alignment using DIAMOND. Nat Methods. 2015;12:59-60.

72. Wattam AR, Davis JJ, Assaf R, Boisvert S, Brettin T, Bun C, et al. Improvements to PATRIC, the all-bacterial Bioinformatics Database and Analysis Resource Center. Nucleic Acids Res. 2017;45: D535-42.

73. Li C, Wen A, Shen B, Lu J, Huang Y, Chang Y. FastCloning: a highly simplified, purification-free, sequence- and ligation-independent PCR cloning method. Bmc Biotechnol. 2011;11:92.

74. Jain S, Caforio A, Fodran P, Lolkema JS, Minnaard AJ, Driessen AJM. Identification of CDP-archaeol synthase, a missing link of ether lipid biosynthesis in Archaea. Chem Biol. 2014;21:1392-401.

75. Miroux B, Walker JE. Over-production of proteins in Escherichia coli: mutant hosts that allow synthesis of some membrane proteins and globular proteins at High Levels. J Mol Biol. 1996;260:289-98.

76. Studier FW. Protein production by auto-induction in high-density shaking cultures. Protein Expres Purif. 2005;41:207-34.

77. Rütters H, Sass H, Cypionka H, Rullkötter J. Phospholipid analysis as a tool to study complex microbial communities in marine sediments. J Microbiol Meth. 2002;48:149-60.

78. Lyons TW. OCEAN SCIENCE: ironing out ocean chemistry at the dawn of animal life. Science. 2008;321:923-4.

79. Parsons JB, Rock CO. Bacterial lipids: metabolism and membrane homeostasis. Prog Lipid Res. 2013;52:249-76.

80. Peterhoff D, Beer B, Rajendran C, Kumpula E, Kapetaniou E, Guldan $\mathrm{H}$, et al. A comprehensive analysis of the geranylgeranylglyceryl phosphate synthase enzyme family identifies novel members and reveals mechanisms of substrate specificity and quaternary structure organization. Mol Microbiol. 2014;92:885-99.

81. Guldan H, Matysik F-M, Bocola M, Sterner R, Babinger P. Functional assignment of an enzyme that catalyzes the synthesis of an Archaea-type ether lipid in bacteria. Angew Chem Int Ed. 2011;50:8188-91.

82. Yokoi T, Isobe K, Yoshimura T, Hemmi H. Archaeal phospholipid biosynthetic pathway reconstructed in Escherichia coli. Archaea 2012;2012:1-9.

83. Isobe K, Ogawa T, Hirose K, Yokoi T, Yoshimura T, Hemmi H. Geranylgeranyl reductase and ferredoxin from methanosarcina acetivorans are required for the synthesis of fully reduced archaeal membrane lipid in Escherichia coli cells. J Bacteriol. 2014;196:417-23.

84. Caforio A, Jain S, Fodran P, Siliakus M, Minnaard AJ, Oost Jvander, et al. Formation of the ether lipids archaetidylglycerol and archaetidylethanolamine in Escherichia coli. Biochem J. 2015;470:343-55

85. Guldan H, Sterner R, Babinger P. Identification and characterization of a bacterial glycerol-1-phosphate dehydrogenase: Ni2 +-dependent AraM from Bacillus subtilis. Biochem-us. 2008;47:7376-84.

86. Chen A, Zhang D, Poulter CD. (S)-geranylgeranylglyceryl phosphate synthase. Purification and characterization of the first pathway-specific enzyme in archaebacterial membrane lipid biosynthesis. J Biol Chem. 1993;268:21701-5.

87. Zhang D, Poulter CD. Biosynthesis of Archaebacterial lipids in Halobacterium halobium and Methanobacterium thermoautotrophicum. J Org Chem. 1993;58:3919-22.

88. Schouten S, Hopmans EC, Sinninghe, Damsté JS. The organic geochemistry of glycerol dialkyl glycerol tetraether lipids: a review. Org Geochem. 2013;54:19-61.

89. Harvey HR, Fallon RD, Patton JS. The effect of organic matter and oxygen on the degradation of bacterial membrane lipids in marine sediments. Geochim Cosmochim Ac. 1986;50:795-804.

90. Schouten S, Middelburg JJ, Hopmans EC, Sinninghe Damsté JS. Fossilization and degradation of intact polar lipids in deep subsurface sediments: a theoretical approach. Geochim Cosmochim Ac. 2010;74:3806-14.

91. Hug LA, Baker BJ, Anantharaman K, Brown CT, Probst AJ, Castelle CJ, et al. A new view of the tree of life. Nat Microbiol. 2016;1:16048. 